\title{
Frequency of Intraoperative Hypotension After the Induction of Anesthesia in Hypertensive Patients with Preoperative Angiotensin- converting Enzyme Inhibitors
}

\author{
Fahad Salim ${ }^{1}$, Fazal Khan ${ }^{1}$, Muhammad Nasir ${ }^{1}$, Rashid Ali ${ }^{2}$, Ayesha Iqbal ${ }^{3}$, Amir Raza ${ }^{1}$ \\ 1. Anaesthesiology, Aga Khan University, Karachi, PAK 2. Chest Medicine, Jinnah Postgraduate Medical Centre,
} Karachi, PAK 3. Oral Pathology, Sir Syed Institute of Medical Sciences, Karachi, PAK

Corresponding author: Fahad Salim, salimfahad23@gmail.com

\begin{abstract}
\section{Introduction}

The renin-angiotensin-aldosterone system (RAAS) is an important target in the treatment of hypertension. Angiotensin-converting enzyme (ACE) inhibitors block the conversion of angiotensin I to angiotensin II. ACE inhibitors not only treat hypertension but also decrease morbidity and mortality in heart failure patients and in patients with acute myocardial infarction. The discontinuation of ACE inhibitors before the surgery is still controversial. To assess the current magnitude of the problem in our population, we aimed to conduct this study, which evaluated the frequency of intraoperative hypotension after the induction of anesthesia in controlled hypertensive patients with preoperative ACE inhibitors.
\end{abstract}

\section{Material and methods}

This descriptive case series study was conducted at a tertiary hospital in a developing country after approval from the Ethics Review Committee. A total of 115 adult patients, from 16 to 60 years of age, who have undergone elective surgery, have controlled hypertension on the desired drugs for at least six months, have no history of any cardiac event, and have taken the drug on the morning of the surgery, were included in the study after written consent. The demographic data of the patients were entered into the proforma. Preoperative systolic, diastolic, and mean arterial pressure were recorded by the researcher or an assignee in the preoperative holding area. The patients were followed in the recovery room by the team conducting the study until 10 minutes after the arrival of the patient in the recovery room. All statistical analyses were performed using Statistical Packages for the Social Sciences version 19 (SPSS Inc., Chicago, IL). p-value $\leqslant 0.05$ was considered significant.

\section{Results}

Received 01/03/2020 Review began 01/06/2020 Review ended 01/06/2020 Published 01/09/2020

๑) Copyright 2020 Salim et al. This is an open access article distributed under the terms of the Creative Commons Attribution License CC-BY 3.0., which permits unrestricted use, distribution, and reproduction in any medium, provided the original author and source are credited.
Of the 115 patients, 56 (48.7\%) patients were in the age group between 51 and 60 years of age; 38 patients were between the ages of 41 and 50 years and only 21 patients were 40 years or less. On gender, 68 patients were female and 47 were male. According to body mass index (BMI), the majority of the patients were in the overweight group, amounting to 53 (46\%), and 86 (74.78\%) patients were known diabetics. Overall, 77 (66.96\%) of the patients developed intraoperative hypotension with 41 (35.65\%) patients requiring the use of vasopressors in order to correct the hypotension. No statistically significant difference was found between demographic and clinical variables.

\section{Conclusion}

Intraoperative hypotension is more frequent in patients with controlled hypertension on ACE inhibitors although more studies need to be conducted on a larger population in order to determine a more definitive result.

Categories: Anesthesiology, Cardiac/Thoracic/Vascular Surgery, Internal Medicine

Keywords: hypotension, hypertension, anesthesia, angiotensin converting enzyme inhibitors, ace inhibitors

\section{Introduction}

The renin-angiotensin-aldosterone system (RAAS) is an important target in the treatment of hypertension. Angiotensin II production is the final common pathway in the renin-angiotensin-aldosterone system. Angiotensin-converting enzyme (ACE) inhibitors block the conversion of angiotensin I to angiotensin II [1]. ACE inhibitors not only treat hypertension but also decrease morbidity and mortality in heart failure patients and in patients with acute myocardial infarction. This class of drug is well-indicated in patients for the treatment of hypertension. Many studies recommended that beta-blockers and alpha 2 agonists should be continued till the operative day, as their discontinuation may cause more harm than benefit. 
Studies regarding ACE inhibitor use are far more conflicting in nature [2-4]. In the past two decades, numerous studies have been done on the use of ACE inhibitors preoperatively [5]. Drenger, in his study on the use of ACE inhibitors in patients undergoing coronary artery bypass grafting $(\mathrm{CABG})$, found that the withdrawal of ACE inhibitors after CABG was associated with nonfatal in-hospital ischemic events. Also, studies such as the one done by Schulte on 36 patients to study the effect of long-term ACE inhibitor concluded that long-term ACE inhibitor use does not aggravate a decrease in blood pressure in minor surgeries [6]. Both authors suggest that the discontinuation of ACE inhibitors doesn't give an additional benefit. In contrast, Nabbi R et al. presented a case report of a 51-year-old female who underwent general anesthesia and developed hypotension on induction despite the discontinuation of the medicine 24 hours prior to the surgery and concluded that angiotensin II receptor blockers (ARBs) along with ACE inhibitors should be withheld 24 hours prior to surgery and possibly longer to elude unnecessary morbidity and mortality [7]. Ryckwaert F et al. and Smith I et al., in their paper 'Changing concepts in anesthesia for daycare surgery,' stated that continuing ACE inhibitors and angiotensin receptor blockers may increase the likelihood of intraoperative hypotension but it will respond to simple treatments without any apparent adverse outcomes [8-9]. Coriat P et al. did a study on 51 patients who continued their ACE inhibitor therapy till the morning of the surgery and concluded that in hypertensive patients chronically treated with ACE inhibitors, maintenance of therapy until the day of surgery may increase the probability of hypotension at induction [10]. One of the most recent studies was conducted by Khan et al. on 92 patients; it showed that 55 patients developed hypotension within 30 minutes of the beginning of surgery; however, they concluded that more studies were needed to be done on a larger population [11]. The rationale of the current study was to assess the current magnitude of the problem in our population; if the results of this study show an increased frequency of intraoperative hypotension, suggestions will be recommended accordingly in the future to manage such complications. So the objective of our study was determining the frequency of intraoperative hypotension after the induction of anesthesia in controlled hypertensive patients with preoperative ACE inhibitors.

\section{Materials And Methods}

This descriptive case series study was conducted at a tertiary hospital in a developing country after approval from the Ethics Review Committee. The calculation of sample size was based on a previous study. Khan MA et al. reported that after the induction of anesthesia, at 30 minutes, hypotension was observed in $59.8 \%$ cases so $\mathrm{p}=59.8 \%$ and margin of error $=9 \%$; therefore, at least 115 patients were included in this study [11]. The non-probability consecutive sampling technique was used. All adult patients from 16 to 60 years who had undergone elective surgery, with controlled hypertension on the desired drugs for at least six months, with no history of any cardiac event, and those who had taken the drug on the morning of the surgery were included in the study. Those with hypotension (systolic blood pressure $<90$ ) at the time of preoperative evaluation, uncontrolled hypertension (systolic blood pressure $>150$ or diastolic blood pressure $>95$ ) at the time of preoperative evaluation, surgery for pathology related to vasoactive substances (carcinoid, pheochromocytoma), left ventricular ejection fraction less than $40 \%$, clinical evidence of decompensated heart failure at the time of preoperative evaluation, and end-stage renal disease were excluded.

Preoperative evaluation was done to assess the patient according to the inclusion and exclusion criteria. Written consent was taken after informing the patient about the study. Upon receiving consent, the demographics data of the patient were entered into the proforma. The primary anesthetist and surgical team were informed about the study. Preoperative systolic, diastolic, and mean arterial pressure were recorded by the researcher or an assignee in the preop holding area. The intraoperative monitoring chart was maintained by the primary anesthesia team and was followed by the research team. The patient was followed in the recovery room by the team conducting the study until 10 minutes after the arrival of the patient in the recovery room. As there is no protocol of withholding ACE inhibitors in our institution, it is understood that the patient had taken the drug prior to surgery so there was no blinding of any sort, however, the primary anesthesia team was informed about the study by the research team. Standard monitoring was done intra and postoperatively (noninvasive blood pressure, oxygen saturation, heart rate, and body temperature). If hypotension developed, it would be at the discretion of the primary anesthesia team when and whether to correct it with the use of intraoperative fluid administration or vasopressor support as they deemed fit and the research team would not interfere with their decisions as long as all the interventions are recorded without fail. The vitals were recorded at an interval of 10 minutes intraoperatively by the primary team and in the recovery room by the recovery room staff.

\section{Data analysis procedure}

All statistical analysis was performed using Statistical Packages for Social Sciences version 19 (SPSS Inc., Chicago, IL). Frequency and percentage were computed for qualitative observations like gender, American Society of Anesthesiologist (ASA) status, and hypotension. Mean and standard deviation were estimated for age, body mass index (BMI), systolic blood pressure (BP). Stratification was done to controlled effect modifiers like age, gender, BMI, and diabetes to observe the rate of hypotension. The chi-square test was used to observe the modifiers' effect on hypotension. $\mathrm{p} \leqslant 0.05$ was considered statistically significant.

\section{Results}




\section{Cureus}

Overall, 115 patients were included in the study based on the inclusion and exclusion criteria. Of the 115 patients, 56 (48.7\%) patients were in the age group between 51 and 60 years old. A total of 38 patients were between 41 and 50 years and only 21 patients were 40 years or less of age. Descriptive statistics of age and duration of anesthesia are described in Table 1.

\begin{tabular}{|c|c|c|}
\hline Statistics & Age (Years) & Duration of Anesthesia (min) \\
\hline Mean \pm SD & $49.02 \pm 8.69$ & $76.61 \pm 33.08$ \\
\hline 95\% Confidence Interval for Mean Lower Bound - Upper Bound & 47.41-50.62 & $70.5-82.72$ \\
\hline Median (IQR) & $50(12)$ & $70(30)$ \\
\hline Minimum & 19 & 20 \\
\hline Maximum & 60 & 200 \\
\hline
\end{tabular}

TABLE 1: Descriptive statistics of age and duration of anesthesia

Out of 115 patients, 68 were female and 47 were male. According to BMI, the majority of the patients were in the overweight group, amounting to 53 (46\%), followed by the group with normal BMI (47 (40\%)) with the obese and morbid obese group comprising 10 (8.7\%) and 5 (4.35\%), respectively. A total of 103 patients were labeled as ASA II and 12 patients were labeled as ASA III due to either uncontrolled diabetes or morbid obesity. There were no ASA IV patients. Of the 115 patients, 86 (74.78\%) patients were known diabetics. Although all the patients were on ACE inhibitors, 31 (29.96\%) patients were also on some other antihypertensives; mostly, these drugs were either diuretics or calcium channel blockers. Intraoperative hypotension was observed in 77 (66.96\%) patients in which 41 (35.65\%) patients required the use of vasopressors to correct the hypotension. A higher frequency of hypotension was noted in the age group between 41 and 50 years of age (73.7\%) although the difference was not statistically significant, as shown in Table 2 .

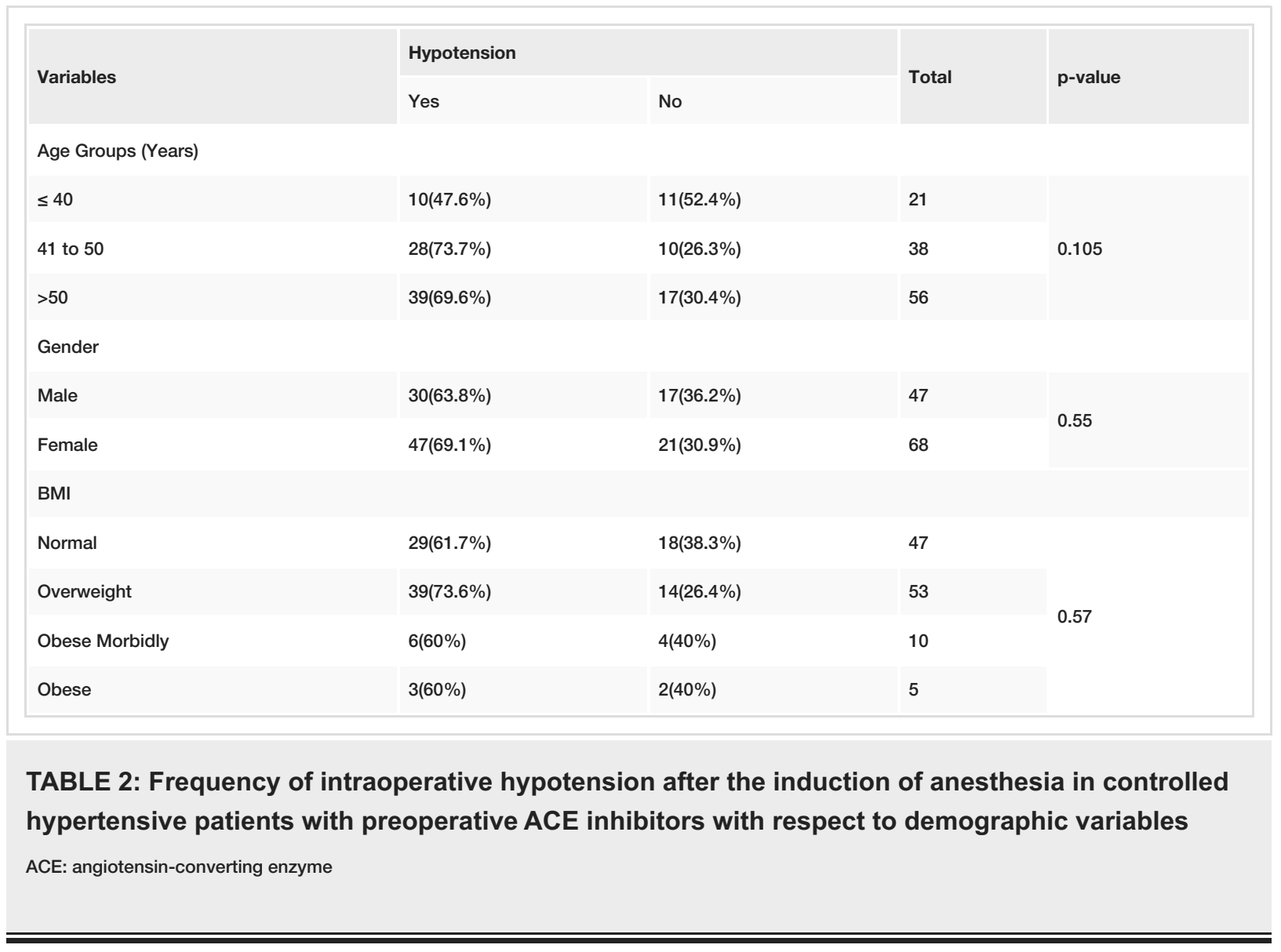


drugs, including ACE inhibitors. Of the total sample size, 31 patients were on antihypertensive therapy apart from ACE inhibitors. These drugs included diuretics, calcium channel blockers, or beta-blockers. Our results showed that 22 out of the 31 (77\%) patients on other antihypertensive therapy developed intraoperative hypotension. Although statically insignificant $(p>0.05)$ in this study, these findings can be compared to those of Colson et al. in an earlier study, which showed that the patients who were receiving combination antihypertensive drugs along with ACE inhibitors, were more prone to hypotension [17]. Similarly, Kheterpal et al. concluded that concomitant diuretic therapy with ACE inhibitors can lead to an increased incidence of intraoperative hypotension in an observational study done in 2006 on 9000 patients [18]. Of the 77 patients who did develop hypotension in our study, 41 patients needed the use of vasopressors to correct the hypotension. This can be compared to the double-blinded, randomized control study done by Schirman and Schurman on 100 patients who said that the patients who received ACE inhibitors had to be given vasopressor support more often ( 17 of the 50 patients ) than patients who didn't receive the drug ( 5 out of 50 patients) but still developed hypotension [19].

Another variable that we observed in this study was age. We divided the subjects into three groups that were less than 40 years (n-21) between 41 and 50(n-38) and the third group aged between 51 and 60 (n-56). It was observed that the younger age group was less prone to intraoperative hypotension as compared to the older age group. These findings are in accordance with the conclusion made by Reich et al. who enlisted ages of more than 50 as a predictor of intraoperative hypotension. Reich et al. also said that ASA III patients were more likely to develop intraoperative hypotension although our study found there was no difference in the development of hypotension in the patients labeled ASA II or ASA III [20]. Diabetes was found in $29(25.22 \%)$ patients and 86 patients were non-diabetics. Of these, 19 patients developed intraoperative hypotension. There is scant literature available that predicts diabetes as a risk factor for intraoperative hypotension for hypertensive patients on ACE inhibitors. Reich et al. didn't find any association of preoperative hypoglycemia with intraoperative hypotension [20]. Furthermore, Kheterpal et al. were unable to confirm insulin-dependent diabetes mellitus as a risk factor for the revised cardiac risk index for patients undergoing general anesthesia in 2009 [21].

In a retrospective review, our study does have its limitations. As this was an observational study, none of the general anesthesia techniques were standardized, which could have affected the results. Other than that, there was no record of patients who had intraoperative difficult airway instrumentation, an implication of fluid therapy, changes in position, or a variety of other potential factors, which might have influenced the results.

\section{Conclusions}

Intraoperative hypotension is more frequent in patients with controlled hypertension on ACE inhibitors although more studies need to be conducted on a larger population in order to determine a more definitive result.

\section{Additional Information \\ Disclosures}

Human subjects: Consent was obtained by all participants in this study. Animal subjects: All authors have confirmed that this study did not involve animal subjects or tissue. Conflicts of interest: In compliance with the ICMJE uniform disclosure form, all authors declare the following: Payment/services info: All authors have declared that no financial support was received from any organization for the submitted work. Financial relationships: All authors have declared that they have no financial relationships at present or within the previous three years with any organizations that might have an interest in the submitted work. Other relationships: All authors have declared that there are no other relationships or activities that could appear to have influenced the submitted work.

\section{References}

1. Anish N, Gabremedhin AM: An encounter with enalapril-induced resistant, life-threatening angioedema at rural health center in Botswana. Indian J Crit Care Med. 2016, 20:613-616. 10.4103/0972-5229.192060

2. Myles PS: Perioperative use of beta-blockers in vascular and endovascular surgery . Br J Anaesth. 2017, 118:948-949. 10.1093/bja/aex145

3. Pai S-L, Chadha RM, Irizarry-Alvarado JM, Renew JR, Aniskevich I: Pharmacologic and perioperative considerations for antihypertensive medications. Curr Clin Pharmacol. 2017, 12:135-140. 10.2174/1574884712666170918152004

4. Stevens RD, Burri H, Tramer MR: Pharmacologic myocardial protection in patients undergoing noncardiac surgery: a quantitative systematic review. Anesth Analg. 2003, 97:623-633. 10.1213/01.ANE.0000074795.68061.16

5. Drenger B, Fontes ML, Miao Y, et al.: Patterns of use of perioperative angiotensin-converting enzyme inhibitors in coronary artery bypass graft surgery with cardiopulmonary bypass. Effects on in-hospital morbidity and mortality. Circulation. 2012, 17:261-269. 10.1161/CIRCULATIONAHA.111.059527

6. Schulte E, Ziegler D, Philippi-Hohne C, Kaczmarczyk G, Boemke W: Angiotensin-converting enzyme inhibition and blood pressure response during total intravenous anaesthesia for minor surgery. Acta Anaesthesiol Scand. 2011, 55:435-443. 10.1111/j.1399-6576.2011.02409.x 
7. Nabbi R, Woehlck HJ, Riess ML: Refractory hypotension during general anesthesia despite preoperative discontinuation of an angiotensin receptor blocker. F1000Res. 2013, 2:12. 10.12688/f1000research.2-12.v1

8. Ryckwaert F, Colson P: Hemodynamic effects of anesthesia in patients with ischemic heart failure chronically treated with angiotensin-converting enzyme inhibitors. Anesth Analg. 1997, 84:945-949.

9. Smith I, Jackson I: Beta-blockers, calcium channel blockers, angiotensin converting enzyme inhibitors and angiotensin receptor blockers: should they be stopped or not before ambulatory anaesthesia. Curr Opin Anaesthesiol. 2010, 23:687-690. 10.1097/ACO.0b013e32833eeb19

10. Coriat $\mathrm{P}$, Richer $\mathrm{C}$, Douraki $\mathrm{T}$, et al.: Influence of chronic angiotensin-converting enzyme inhibition on anesthetic induction. Anesthesiology. 1994, 81:299-307. 10.1097/00000542-199408000-00006

11. Khan MA, Shujaat S, Iqbal MR, Hanif MD, Ahmed A: Intra-operative hypotension. Induction of anesthesia in patients continuing their routine dose of angiotensin system inhibitor therapy before surgery. Professional Med J. 2012, 19:695-699.

12. Ding Q, Zhang Z, Liu H, et al.: Perioperative use of renin-angiotensin system inhibitors and outcomes in patients undergoing cardiac surgery. Nat Commun. 2019, 10:1-10. 10.1038/s41467-019-11678-9

13. Behnia R, Molteni A, Igic R: Angiotensin-converting enzyme inhibitors: mechanisms of action and implications in anesthesia practice. Curr Pharm Des. 2003, 9:763-776. 10.2174/1381612033455413

14. Pigott DW, Nagle C, Allman K, Westaby S, Evans RD: Effect of omitting regular ACE inhibitor medication before cardiac surgery on haemodynamic variables and vasoactive drug requirements. Br J Anaesth. 1999, 83:715-720. 10.1093/bja/83.5.715

15. Comfere T, Sprung J, Kumar MM, et al.: Angiotensin system inhibitors in a general surgical population . Anesth Analg. 2005, 100:636-644. 10.1213/01.ANE.0000146521.68059.A1

16. Rajgopal R, Rajan S, Sapru K, Paul J: Effect of pre-operative discontinuation of angiotensin-converting enzyme inhibitors or angiotensin II receptor antagonists on intra-operative arterial pressures after induction of general anesthesia. Anesth Essays Res. 2014, 8:32-35. 10.4103/0259-1162.128903

17. Colson P, Saussine M, Séguin JR, Cuchet D, ChaptalG PA, Roquefeuil B: Hemodynamic effects of anesthesia in patients chronically treated with angiotensin-converting enzyme inhibitors. Anesth Analg. 1992, 74:805808. 10.1213/00000539-199206000-00005

18. Kheterpal S, Khodaparast O, Shanks A, O’Reilly M, Tremper KK: Chronic angiotensin-converting enzyme inhibitor or angiotensin receptor blocker therapy combined with diuretic therapy is associated with increased episodes of hypotension in noncardiac surgery. J Cardiothorac Vasc Anesth. 2008, 30:180-186. 10.1053/j.jvca.2007.12.020

19. Schirmer U, Schürmann W: Preoperative administration of angiotensin-converting enzyme inhibitors [Article in German]. Anaesthesist. 2007, 56:557-561. 10.1007/s00101-007-1177-x

20. Reich DL, Hossain S, Krol M, Baez B, Patel P, Bernstein A, Bodian CA: Predictors of hypotension after induction of general anesthesia. Anesth Analg. 2005, 101:622-628. 10.1213/01.ANE.0000175214.38450.91

21. Kheterpal S, O'Reilly M, Englesbe MJ, et al.: Preoperative and intraoperative predictors of cardiac adverse events after general, vascular, and urological surgery. Anesthesiology. 2009, 110:58-66. 10.1097/ALN.0b013e318190b6dc 